\title{
Analyzing the Current Status of India in Global Scenario with Reference to COVID-19 Pandemic
}

\author{
Dharmendra K. Yadav \\ Department of Statistics \& Demography (S\&D) \\ National Institute of Health and Family Welfare (NIHFW), New Delhi-110067, INDIA \\ Email: drdkyadav@nihfw.org \\ Sharvari Shukla \\ Symbiosis Statistical Institute, Pune, India- 411016 \\ Email: director@ssi.edu.in \\ S. K. Yadav* \\ Department of Statistics \\ School of Physical and Decision Sciences \\ Babasaheb Bhimrao Ambedkar University (A Central University), Lucknow-226025, INDIA \\ Corresponding Author Email: drskystats@gmail.com
}

\begin{abstract}
The crux of the paper is to present a detailed analysis of COVID-19 data which is available on global basis. This analysis is performed using some specific package of $\mathrm{R}$ software. It provides various insights from the data and help to understand the current status of this pandemic in India so that effective measures can be formulated by policymakers. These insights include global summary of this disease, growth rate of this pandemic and performance of SIR model for the given global data. The analysis has been presented in different tables and graphs to understand the outputs of the problem in a more detailed point of view.
\end{abstract}

Keywords: COVID-19, Disease Modelling, SIR Model, R software

\section{INTRODUCTION}

At present entire human community is facing a very crucial stage by the spread of COVID19. WHO has declared it a global pandemic (L.-s. Wang et al., 2020) due to its deadly nature. This pandemic has its origin in Wuhan province of China during December. 2019 in the form of a pneumonia case was reported (Huang et al., 2020). This case was declared novel coronavirus pneumonia by the health experts. Later on WHO declared its official name as COVID-19 (Huang et al., 2020). 
Social distancing, washing hands frequently, avoiding touching the mouth, nose, and face etc are important preventive measures for COVID-19 are suggested (WHO, 2020).

In India the first case of COVID-19 was reported on 30th January 2020 with origin from China (PIB, 2020). Now it has been spread in all the states and UTs of the country. As per our analysis date (16 June 2020) there are 3,43,091 total confirm cases, with 180013 recoveries and 9900 deaths (Covid-19.in, 2020) in the country.

Administration and health officials are facing lot of problem to accommodate patients of COVID-19. So, development of some prediction tools to know expected number of cases in upcoming time is the need of hour for future preparations.( Tobías, 2020; L. Wang et al., 2020; L.-s. Wang et al., 2020). Such prediction techniques can make future preparation more easy to control this pandemic. We can also learn from the other countries and past experience of our own. So we must focus on developing such prediction tools.

In this paper we have analyzed live data of COVID-19 (2020) as on 16 June 2020 by using covid19.analytics (2020) package of $\mathrm{R}$ software. We are using various statistical and epidemic models for future prediction of this pandemic. The insights obtained from such analysis can provide blueprints for effective policy making regarding the prevention and control of this outbreak. The paper has been presented in various sections. Section-2 represents the review of literature of various epidemiological models used for transmission dynamics of infectious diseases. In Section-3, the material and methods have been discussed regarding the present investigation. Under this section, the mathematics of the model, the basic reproductive number and the data used have been described. Section-4 represents the summary of the outputs of the analysis. The overall summary and findings have been discussed in section-5. In Section-6 the concluding remarks have been presented and the paper ends with the references.

\section{REVIEW OF LITERATURE}

Mathematical modeling has significant contribution in predicting and cotrolling of any disease. With the help of model we can recognize the nature, effects and spread pattern of the disease. Modelling can help to study the implications of disease in the future time in terms of 
trends. We can also study the epidemiological trends of disease. Various researchers have devoted their work to develop mathematical models for infectious diseases. Such mathematical models may be simple trend line or sophisticated computer programming based SIR model.(Anderson \& May 1991; Diekmann \& Heesterbeek 2000).

In any mathematical model of infectious disease there are two most important factors:

i. The basic reproductive number (Ro)

ii. Generation time

These two factors jointly make outbreak prediction of any infectious disease. (Anderson \& May 1991; Diekmann \& Heesterbeek 2000; Wallinga \& Teunis 2004). These models highly depend on the nature of available data of disease. With help of relevant data these models provide robust estimates of the parameters and their distribution. .

A lot of work has been done in the direction of forecasting and mathematical modeling of many infectious diseases worldwide including COVID-19. Most of the research work is devoted to predict the expected cases of this pandemic in near future. Now it high time to develop methodologies which can predict average time duration to control this pandemic.

Kermack and McKendrick (1927) has discussed and analyzed the transmission mechanism of many infectious diseases using various models. In their model they have divided the whole population $\mathrm{N}$ into three different groups namely $\mathrm{S}, I$ and $R$ which denote the susceptible, infected and recovered groups of respectively. The susceptible group contains those units which at present are healthy but are suspected to be infected by disease in near future, and the size of this sub-population is denoted by $S$, the infected class is that group of population which is already infected by the disease, denoted by I and R denotes that group of population which is recovered from the disease. Till now many authors have worked on the transmission dynamics modeling of various infectious diseases. The latest includes Rihan and Anwar (2012) who considered a SIR epidemiological model where the susceptible individuals are supposed to satisfy the logistic equation and the incidence term is of saturated form with the susceptible. They investigated the nature of the model and shown the asymptotic stability of the model for the given steady states. Huppert and Katriel (2013) discussed the reliability of disease predictions provided by transmission models. Chauhan et 
al. (2014) had studied a SIR model with and without vaccination for the infectious diseases. The linear as well as the global stabilities of the model for both the situations were discussed and the comparison was also made for both the situations for the existence of the disease-free equilibrium point and endemic equilibrium point. Li and Zhang (2017) suggested a modified SIR model for disease modelling along with the nonlinear incidence and recovery rates. They also discussed the nature of the model with government intervention and with different hospitalization conditions in the spread of the infectious diseases.

Currently Dhanwant and Ramanathan (2020) worked on the forecasting of Covid 19 pandemic using SIR model. Wangping et al. (2020) analyzed the time-series data on COVID-19 from Jan 222020 to Apr 02 2020. They used extended SIR (eSIR) model for transmission dynamics of COVID-19. They worked on the effects of different intervention measures in different non-identical periods and estimated and forecasted the epidemic trend in Italy. They found the basic reproductive number through Markov Chain Monte Carlo simulation technique and obtained the posterior mean and 95\% credible interval (CI) for it. Binti et al. (2020) described in their paper predicted and forecasted the COVID-19 cases, deaths, and recoveries using the mathematical disease predictive modelling. They also performed the sentiment analysis of people on many health related issues.

Mahmud and Lim (2020) applied the Susceptible, Exposed, Infectious and Removed (SEIR) mathematical model for disease transmission dynamics and forecasted the trend of COVID-19 pandemic in Malaysia utilizing data from March 17 to 27, 2020. Boudrioua and Boudrioua (2020) predicted the per day cases of infections of Corona virus (COVID-19) in Algeria. They applied the SIR epidemiological model for data from 25 February 2020 to 24 April 2020 and predicted the disease and further developed two SIR models, one optimal model and another epidemiological model for the worst-condition of COVID-19. Giordano et al. (2020) proposed a new epidemiological model for the prediction of the epidemic to help for the effective planning of the control strategy. The model described the epidemic in eight stages of infection: susceptible (S), infected (I), diagnosed (D), ailing (A), recognized (R), threatened $(\mathrm{T})$, healed $(\mathrm{H})$ and extinct $(\mathrm{E})$, collectively termed SIDARTHE. Through SIDARTHE model they differentiated between the infected individuals on the basis of the diagnosis of the infection and the severity of their symptoms. 


\section{MATERIAL AND METHODS}

Several statistical methodologies like Regression analysis, time series analysis and epidemiological models have been used for analysing of the data set on Covid-19. As Covid19 is an infectious disease, epidemiological models are the most suitable tools to predict the problem so that to make better policies to overcome the problem. In this paper, we have used the SIR epidemiological model to analyze the transmission dynamics of Covid-19 pandemic. Various summary reports will give an idea about the present situation of India on different criteria of COVID-19. Insights obtained from such reports provide blueprints to policy makers and health administrators to formulate effective policy and guideline to control this pandemic.

\subsection{SIR (Susceptible-Infected-Recovered) Model Description}

SIR is an epidemic model that shows the change of infection rate over time. As illustrated in the figure below, the SIR model characterizes the dynamic interplay among the susceptible individuals (S), infectious individuals (I) and recovered/ deceased individuals (R) in a certain place. In the SIR model, the susceptible individuals may become infectious individuals over time, which depends on the spread rate of the virus, often called the contact rate. Recovered individuals are supposed to be immune and thus cannot become susceptible again. The following Figure-1 represents the pictorial diagram of the transmission dynamics of SIR model.

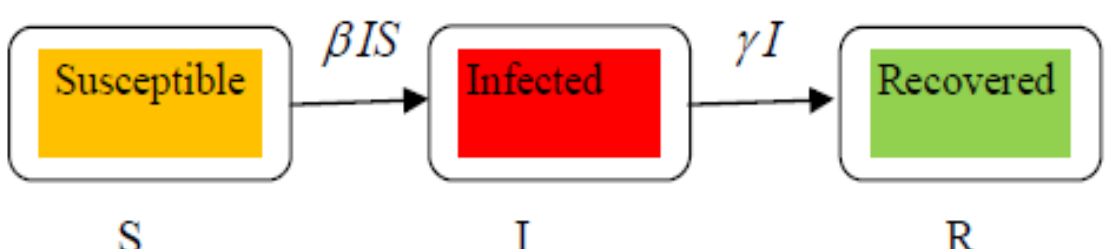

Figure-1. Illustration of the SIR model

To characterize the dynamics in the mathematical form, let the parameters of the model at time $\mathrm{t}$ are as follows:

- $S_{t}$ : Total susceptible individuals

- $I_{t}$ : Total infectious individuals

- $R_{t}$ : Total recovered/ deceased/ immune individuals. 
To simplify the analysis, it is assumed that the total population under consideration is fixed as $\mathrm{N}$. The evolving ordinary differential equations of the SIR model with above parameters over time are defined as follows:

$$
\begin{aligned}
\frac{d S_{t}}{d t} & =-\frac{\beta I_{t} S_{t}}{N} \\
\frac{d I_{t}}{d t} & =\frac{\beta I_{t} S_{t}}{N}-\gamma I_{t} \\
\frac{d R_{t}}{d t} & =\gamma I_{t}
\end{aligned}
$$

Where, $N=S+I+R$ is the total population or $N(t)=S(t)+I(t)+R(t)$ is the total population at time $t, \beta$ is the contact rate between the Susceptible and Infectious groups, and $\gamma$ is the transition rate between the Infectious individuals, it will decrease by a quantity $\frac{\beta I_{t} S_{t}}{N}$, who will transmit into the infectious group. Apart from the increase from the transition of susceptible individuals, the size of the infectious group will also decrease by a factor $\gamma$. In the COVID-19 case, the infection ratio $\beta$ could be scaled with $\frac{1}{s_{t}}$, since the population is not fully mixed and people are quarantined at home.

\subsection{The Basic Reproduction Number $R_{0}$}

The Basic Reproduction Number, denoted by $R_{0}$ is the average number of infection cases on second stage or secondary cases which are produced from an average first stage or primary cases in the whole susceptible population. Thus it is the rate of infection by which new infections are produced through an infected individual in the whole susceptible population. It measures the maximum reproductive potential for an infectious disease. The infectious disease will spread if $R_{0}>1$ that is the disease will be transmitted to more than one host. $R_{0}$ depends on the disease and host population and it is different for different infectious diseases for instance $R_{0}=2.6$ for TB in cattle, $R_{0}=[34]$ for influenza in humans. $R_{0}=[3.56]$ for small pox in humans and $R_{0}=[1618]$ for Measles in humans. For an infectious disease, $R_{0}=\frac{\beta}{\gamma}$ with an average infectious period $\frac{1}{\gamma}$ and transmission rate $\beta$.

\subsection{Data Description:}

For our study we have used live data from covid 19.analytics (2020) package of R studio. This data is updated and analyzed globally on daily basis by the Johns Hopkins University Center for Systems Science and Engineering (JHU CSSE) data repository (2020). This data 
set is available in two forms, as a time series sequences and aggregated for the last day with greater spatial resolution.

The analysis has been done on the following criteria:

\section{SUMMARY}

Summary regarding covid-19 has been generated worldwide. It has shown the performance of top 10 countries of the world with reference to this pandemic. There are total 5 summary reports are generated based on different criteria. This is based on data available till 16 June 2020 .

Summary I: First summary report is based on performance of top 10 countries of the world selected on the basis of total number of confirm cases of covid-19.From the table given below it is clear that US has highest number of Covid-19 confirmed cases.

\section{SUMMARY-I}

TS-CONFIRMED Cases -- Data dated: 2020-06-15 :: 2020-06-16 15:48:27

Number of Countries/Regions reported: 188

Number of Cities/Provinces reported: 82

Unique number of distinct geographical locations combined: 266

Worldwide ts-confirmed Totals: 8034461

\begin{tabular}{|l|l|l|l|l|l|l|l|l|l|}
\hline S.No & Country.Region & Totals & $\begin{array}{l}\text { Global } \\
\text { Perc }\end{array}$ & $\begin{array}{l}\text { Last } \\
\text { Day } \\
\text { Change }\end{array}$ & $\mathbf{t - 2}$ & $\mathbf{t}-3$ & $\mathbf{t}-\mathbf{7}$ & $\mathbf{t - 1 4}$ & $\mathbf{t}-30$ \\
\hline $\mathbf{1}$ & US & 2114026 & 26.31 & 19968 & 19532 & 25540 & 18087 & 20891 & 19004 \\
\hline $\mathbf{2}$ & Brazil & 888271 & 11.06 & 20647 & 17110 & 21704 & 32091 & 28936 & 7569 \\
\hline $\mathbf{3}$ & Russia & 536484 & 6.68 & 8217 & 8809 & 8697 & 8587 & 8858 & 9709 \\
\hline $\mathbf{4}$ & India & 343091 & 4.27 & 10667 & 11502 & 11929 & 10218 & 8821 & 5050 \\
\hline $\mathbf{5}$ & UK & 296857 & 3.69 & 968 & 1514 & 1425 & 1741 & 1653 & 3534 \\
\hline $\mathbf{6}$ & Spain & 244109 & 3.04 & 181 & 323 & 396 & 249 & 294 & 0 \\
\hline $\mathbf{7}$ & Italy & 237290 & 2.95 & 301 & 338 & 346 & 283 & 318 & 675 \\
\hline $\mathbf{8}$ & Peru & 232992 & 2.90 & 3256 & 8987 & 5961 & 4040 & 0 & 3732 \\
\hline $\mathbf{9}$ & Iran & 189876 & 2.36 & 2449 & 2472 & 2430 & 2095 & 3117 & 1806 \\
\hline $\mathbf{1 0}$ & France & 189670 & 2.36 & 68 & 291 & 393 & 141 & -972 & 33 \\
\hline
\end{tabular}


Global Perc. Average: 0.38 (sd: 1.87$)$

Global Perc. Average in top $10: 6.56$ (sd: 7.44$)$

Interpretation: From summary table it is clear that India is at $4^{\text {th }}$ rank among top 10 countries in terms of total confirmed cases of COVID-19.

Summary II- The second summary report is based on total number of death cases due to covid -19. Here it is clear that US is at top among the list of top ten countries in terms of total death cases due to this pandemic.

\section{SUMMARY-II}

TS-DEATHS Cases -- Data dated: 2020-06-15 :: 2020-06-16 15:48:28

Number of Countries/Regions reported: 188

Number of Cities/Provinces reported: 82

Unique number of distinct geographical locations combined: 266

Worldwide ts-deaths Totals: 436899

\begin{tabular}{|l|l|l|l|l|l|l|l|l|l|}
\hline S.No & Country.Region & Totals & Percentage & $\begin{array}{l}\text { Last } \\
\text { Day } \\
\text { Change }\end{array}$ & $\mathbf{t}-2$ & $\mathbf{t}-3$ & $\mathbf{t}-\mathbf{7}$ & $\mathbf{t}-14$ & $\begin{array}{l}\text { t- } \\
\mathbf{3 0}\end{array}$ \\
\hline $\mathbf{1}$ & US & 116127 & 5.49 & 395 & 296 & 767 & 946 & 1031 & 809 \\
\hline $\mathbf{2}$ & Brazil & 43959 & 4.95 & 627 & 612 & 892 & 1272 & 1262 & 456 \\
\hline $\mathbf{3}$ & UK & 41736 & 14.06 & 38 & 36 & 181 & 286 & 324 & 170 \\
\hline $\mathbf{4}$ & Italy & 34371 & 14.48 & 26 & 44 & 78 & 79 & 55 & 145 \\
\hline $\mathbf{5}$ & France & 29375 & 15.49 & 29 & 7 & 24 & 84 & 107 & 579 \\
\hline $\mathbf{6}$ & Spain & 27136 & 11.12 & 0 & 0 & 0 & 0 & 0 & 0 \\
\hline $\mathbf{7}$ & Mexico & 17580 & 11.70 & 439 & 269 & 424 & 596 & 470 & 132 \\
\hline $\mathbf{8}$ & India & 9900 & 2.89 & 380 & 325 & 311 & 277 & 221 & 154 \\
\hline $\mathbf{9}$ & Belgium & 9661 & 16.07 & 6 & 5 & 4 & 13 & 19 & 47 \\
\hline $\mathbf{1 0}$ & Iran & 8950 & 4.71 & 113 & 107 & 71 & 74 & 64 & 51 \\
\hline
\end{tabular}

Interpretation: From summary table it is clear that India is at $8^{\text {th }}$ position among top 10 countries in terms of total deaths due to COVID-19. 


\section{Summary-III}

This third report is generated on the basis of total number of recovered cases of this pandemic. Here US has highest number of recovered cases.

\begin{tabular}{|c|c|c|c|c|c|c|c|c|}
\hline & & & UMMA & III. & & & & \\
\hline TS-R & $\begin{array}{r}\text { ECOVERED Cas } \\
\text { Numb } \\
\text { Nuique numbe }\end{array}$ & $\begin{array}{l}\text { S -- Dat: } \\
\text { er of Col } \\
\text { aber of } C \\
\text { of distin }\end{array}$ & $\begin{array}{l}\text { dated: } 2 \\
\text { ntries/Re } \\
\text { ties/Prov } \\
\text { t geogra }\end{array}$ & $\begin{array}{l}020-06- \\
\text { jions re } \\
\text { nces re } \\
\text { hical lo }\end{array}$ & $\begin{array}{l}15:: 2 \\
\text { ported } \\
\text { ported } \\
\text { cations }\end{array}$ & $\begin{array}{l}20-06-1 \\
188 \\
68 \\
\text { combin }\end{array}$ & $\begin{array}{l}615: 48 \\
d: 253\end{array}$ & \\
\hline & Wol & ldwide ts & recovere & Total & s: 3857 & & & \\
\hline S.No & Country.Region & Totals & $\begin{array}{l}\text { Last } \\
\text { Day } \\
\text { Change }\end{array}$ & $t-2$ & $\mathrm{t}-3$ & $t-7$ & t-14 & t-30 \\
\hline $\mathbf{1}$ & US & 576334 & $14518^{\circ}$ & 5210 & 9220 & 6333 & 5637 & 3889 \\
\hline 2 & Brazil & 477709 & 8568 & 9705 & 14313 & 18480 & 12558 & 4450 \\
\hline 3 & Russia & 284021 & 4485 & 5408 & 5266 & 11691 & 11088 & 4207 \\
\hline 4 & India & 180013 & 10215 & 7419 & 8049 & 5575 & 4531 & 2571 \\
\hline 5 & Italy & 177010 & 640 & 1505 & 1780 & 2062 & 1737 & 2366 \\
\hline 6 & Germany & 172692 & 603 & 119 & 435 & 573 & 977 & 1411 \\
\hline 7 & Turkey & 152364 & 947 & 1330 & 985 & 3218 & 974 & 1825 \\
\hline 8 & Iran & 150590 & 1916 & 1926 & 2099 & 2097 & 2073 & 1317 \\
\hline 9 & Spain & 150376 & 0 & 0 & 0 & 0 & 0 & 0 \\
\hline 10 & Chile & 148792 & 5088 & 6408 & 5938 & 5113 & 41227 & 1199 \\
\hline
\end{tabular}

Interpretation: From summary table it is clear that India is at $4^{\text {th }}$ position among top 10 countries in terms of total recovered cases of COVID-19.

\section{Summary IV:}

This summary report is generated on the basis of total confirm cases but with some additional columns. Here short listing is done on the basis of total percentage of deaths among confirmed cases. 


\section{SUMMARY IV}

\section{AGGREGATED Data -- ORDERED BY CONFIRMED Cases -- \\ Data dated: 2020-06-16 :: 2020-06-16 15:48:29}

Number of Countries/Regions reported: 188

Number of Cities/Provinces reported: 549

Unique number of distinct geographical locations combined: 3746

\begin{tabular}{|c|c|c|c|c|c|c|c|c|c|}
\hline $\begin{array}{l}\text { S. } \\
\text { No }\end{array}$ & Location & $\begin{array}{c}\text { Confir } \\
\text { med }\end{array}$ & $\begin{array}{c}\text { Perc. } \\
\text { Confir } \\
\text { med }\end{array}$ & $\begin{array}{c}\text { Deat } \\
\text { hs }\end{array}$ & $\begin{array}{l}\text { Perc } \\
\text { Deat } \\
\text { hs }\end{array}$ & $\begin{array}{c}\text { Recove } \\
\text { red }\end{array}$ & $\begin{array}{c}\text { Perc.Recov } \\
\text { ered }\end{array}$ & $\begin{array}{l}\text { Acti } \\
\text { ve }\end{array}$ & $\begin{array}{l}\text { Perc } \\
\text { Acti } \\
\text { ve }\end{array}$ \\
\hline 1 & $\begin{array}{l}\text { New York } \\
\text { City, New } \\
\text { York, US }\end{array}$ & 210259 & 2.62 & $\begin{array}{l}2212 \\
4\end{array}$ & $\begin{array}{l}10.5 \\
2\end{array}$ & 0 & 0.00 & $\begin{array}{l}1881 \\
35\end{array}$ & $\begin{array}{l}89.4 \\
8\end{array}$ \\
\hline 2 & $\begin{array}{l}\text { Moscow, } \\
\text { Russia }\end{array}$ & 207264 & 2.58 & 3334 & 1.61 & 123240 & 59.46 & $\begin{array}{l}8069 \\
0\end{array}$ & $\begin{array}{l}38.9 \\
3\end{array}$ \\
\hline 3 & Iran & 189876 & 2.36 & 8950 & 4.71 & 150590 & 79.31 & $\begin{array}{l}3033 \\
6\end{array}$ & $\begin{array}{l}15.9 \\
8\end{array}$ \\
\hline 4 & France & 189670 & 2.36 & $\begin{array}{l}2937 \\
5\end{array}$ & $\begin{array}{l}15.4 \\
9\end{array}$ & 69719 & 36.76 & $\begin{array}{l}9057 \\
6\end{array}$ & $\begin{array}{l}47.7 \\
5\end{array}$ \\
\hline 5 & $\begin{array}{l}\text { Sao Paulo, } \\
\text { Brazil }\end{array}$ & 181460 & 2.26 & $\begin{array}{l}1076 \\
7\end{array}$ & 5.93 & 49295 & 27.17 & $\begin{array}{l}1213 \\
98\end{array}$ & $\begin{array}{l}66.9 \\
0\end{array}$ \\
\hline 6 & Turkey & 179831 & 2.24 & 4825 & 2.68 & 152364 & 84.73 & $\begin{array}{l}2264 \\
2\end{array}$ & $\begin{array}{l}12.5 \\
9\end{array}$ \\
\hline 7 & $\begin{array}{l}\text { England, } \\
\text { United } \\
\text { Kingdom }\end{array}$ & 157293 & 1.96 & $\begin{array}{l}3729 \\
9\end{array}$ & $\begin{array}{l}23.7 \\
1\end{array}$ & 0 & 0.00 & $\begin{array}{l}1199 \\
94\end{array}$ & $\begin{array}{l}76.2 \\
9\end{array}$ \\
\hline 8 & $\begin{array}{l}\text { Metropolit } \\
\text { ana, Chile }\end{array}$ & 144280 & 1.80 & 2913 & 2.02 & 0 & 0.00 & $\begin{array}{l}1413 \\
67\end{array}$ & $\begin{array}{l}97.9 \\
8\end{array}$ \\
\hline 9 & $\begin{array}{l}\text { Lima, } \\
\text { Peru }\end{array}$ & 134008 & 1.67 & 3083 & 2.30 & 0 & 0.00 & $\begin{array}{l}1309 \\
25\end{array}$ & $\begin{array}{l}97.7 \\
0\end{array}$ \\
\hline 10 & $\begin{array}{l}\text { Saudi } \\
\text { Arabia }\end{array}$ & 132048 & 1.64 & 1011 & 0.77 & 87890 & 66.56 & $\begin{array}{l}4314 \\
7\end{array}$ & $\begin{array}{l}32.6 \\
8\end{array}$ \\
\hline
\end{tabular}

Interpretation: From summary table it is clear that no city of India is among top 10 cities of COVID-19 affected cities of the world.

Summary V: This summary report is prepared on the basis of total confirm cases, total deaths, total recovered cases, total active cases along with their percentages. Worldwide totals, averages and standard deviations are also given in this report. 


\section{SUMMARY V}

\section{AGGREGATED Data -- ORDERED BY ACTIVE Cases --}

Data dated: 2020-06-16 :: 2020-06-16 15:48:29

Number of Countries/Regions reported: 188

Number of Cities/Provinces reported: 549

Unique number of distinct geographical locations combined: 3746

\begin{tabular}{|c|c|c|c|c|c|c|c|c|c|}
\hline $\begin{array}{c}\text { S.N } \\
\mathbf{0}\end{array}$ & Location & $\begin{array}{l}\text { Confir } \\
\text { med }\end{array}$ & $\begin{array}{c}\text { Perc. } \\
\text { Confir } \\
\text { med }\end{array}$ & Deaths & $\begin{array}{l}\text { Perc. } \\
\text { Death } \\
\text { S }\end{array}$ & $\begin{array}{c}\text { Recover } \\
\text { ed }\end{array}$ & $\begin{array}{c}\text { Perc.Recov } \\
\text { ered }\end{array}$ & $\begin{array}{c}\text { Activ } \\
\text { e }\end{array}$ & $\begin{array}{l}\text { Perc } \\
\text { Acti } \\
\text { ve }\end{array}$ \\
\hline 1 & $\begin{array}{l}\text { New York } \\
\text { City, New } \\
\text { York, US }\end{array}$ & 210259 & 2.62 & 22124 & 10.52 & 0 & 0.00 & $\begin{array}{l}1881 \\
35\end{array}$ & $\begin{array}{l}89.4 \\
8\end{array}$ \\
\hline 2 & $\begin{array}{l}\text { Metropolit } \\
\text { ana, Chile }\end{array}$ & 144280 & 1.80 & 2913 & 2.02 & 0 & 0.00 & $\begin{array}{l}1413 \\
67\end{array}$ & $\begin{array}{l}97.9 \\
8\end{array}$ \\
\hline 3 & Lima, Peru & 134008 & 1.67 & 3083 & 2.30 & 0 & 0.00 & $\begin{array}{l}1309 \\
25\end{array}$ & $\begin{array}{l}97.7 \\
0\end{array}$ \\
\hline 4 & \begin{tabular}{|c|} 
Sao \\
Paulo, \\
Brazil \\
\end{tabular} & 181460 & 2.26 & 10767 & 5.93 & 49295 & 27.17 & $\begin{array}{l}1213 \\
98\end{array}$ & $\begin{array}{l}66.9 \\
0\end{array}$ \\
\hline 5 & $\begin{array}{l}\text { England, } \\
\text { United } \\
\text { Kingdom } \\
\end{array}$ & 157293 & 1.96 & 37299 & 23.71 & 0 & 0.00 & $\begin{array}{l}1199 \\
94\end{array}$ & $\begin{array}{l}76.2 \\
9\end{array}$ \\
\hline 6 & $\begin{array}{l}\text { Unknown, } \\
\text { United } \\
\text { Kingdom }\end{array}$ & 104221 & 1.30 & 0 & 0.00 & 0 & 0.00 & $\begin{array}{l}1042 \\
21\end{array}$ & $\begin{array}{l}100 . \\
00\end{array}$ \\
\hline 7 & France & 189670 & 2.36 & 29375 & 15.49 & 69719 & 36.76 & $\begin{array}{l}9057 \\
6\end{array}$ & $\begin{array}{l}47.7 \\
5\end{array}$ \\
\hline 8 & \begin{tabular}{|l|} 
Cook, \\
Illinois, US
\end{tabular} & 85184 & 1.06 & 4206 & 4.94 & 0 & 0.00 & $\begin{array}{l}8097 \\
8\end{array}$ & $\begin{array}{l}95.0 \\
6\end{array}$ \\
\hline 9 & $\begin{array}{l}\text { Moscow, } \\
\text { Russia }\end{array}$ & 207264 & 2.58 & 3334 & 1.61 & 123240 & 59.46 & $\begin{array}{l}8069 \\
0\end{array}$ & $\begin{array}{l}38.9 \\
3\end{array}$ \\
\hline \multirow[t]{4}{*}{10} & \begin{tabular}{|l|} 
Los \\
Angeles, \\
California, \\
US \\
\end{tabular} & 73832 & 0.92 & 2926 & 3.96 & 0 & 0.00 & $\begin{array}{l}7090 \\
6\end{array}$ & $\begin{array}{l}96.0 \\
4\end{array}$ \\
\hline & & $\begin{array}{l}\text { Confir } \\
\text { med }\end{array}$ & Deaths & $\begin{array}{l}\text { Recover } \\
\text { ed }\end{array}$ & Active & & & & \\
\hline & Totals & 8034504 & 436899 & 3857339 & $\begin{array}{l}36672 \\
90 \\
\end{array}$ & & & & \\
\hline & Average & 2144.82 & 116.63 & 1029.72 & 978.99 & & & & \\
\hline
\end{tabular}




\begin{tabular}{|l|l|l|l|l|l|l|l|l|}
$\begin{array}{l}\text { Standard } \\
\text { Deviation }\end{array}$ & 11355.7 & 1023.32 & $\begin{array}{l}11537.6 \\
3\end{array}$ & $\begin{array}{l}13087 . \\
73\end{array}$ & & & & \\
\hline
\end{tabular}

Interpretation: From summary table it is clear that no city of India is among top 10 cities of the world in terms of total active cases of COVID-19.

\section{OVERALL SUMMARY}

The overall summary is given as:

\begin{tabular}{|c|c|c|}
\hline \multicolumn{3}{|c|}{ OVERALL SUMMARY } \\
\hline \multicolumn{3}{|c|}{ Time Series Worldwide Totals } \\
\hline ts-confirmed & 436899 & ts-recovered \\
\hline 8034461 & $5.44 \%$ & 3857338 \\
& ts-deaths & $48.01 \%$ \\
\hline \multicolumn{3}{|c|}{ Time Series Worldwide Averages } \\
\hline ts-confirmed & 1642.48 & ts-recovered \\
\hline 30204.74 & $5.44 \%$ & 15246.4 \\
& ts-deaths & $50.48 \%$ \\
\hline ts-confirmed & 8728.4 & ts-recovered \\
\hline 150246.61 & $5.81 \%$ & 57482.64 \\
& Time Series Worldwide Standard Deviations & $38.26 \%$ \\
\hline
\end{tabular}

* Statistical estimators computed considering 266/266/253 independent reported entries per case-type

i. Growth Rate: In India growth rate of Covid-19 has been started increasing from the month of March 2020. Figure-1 shows the number of changes and the growth rate of Covid-19 in India since the beginning of the pandemic.
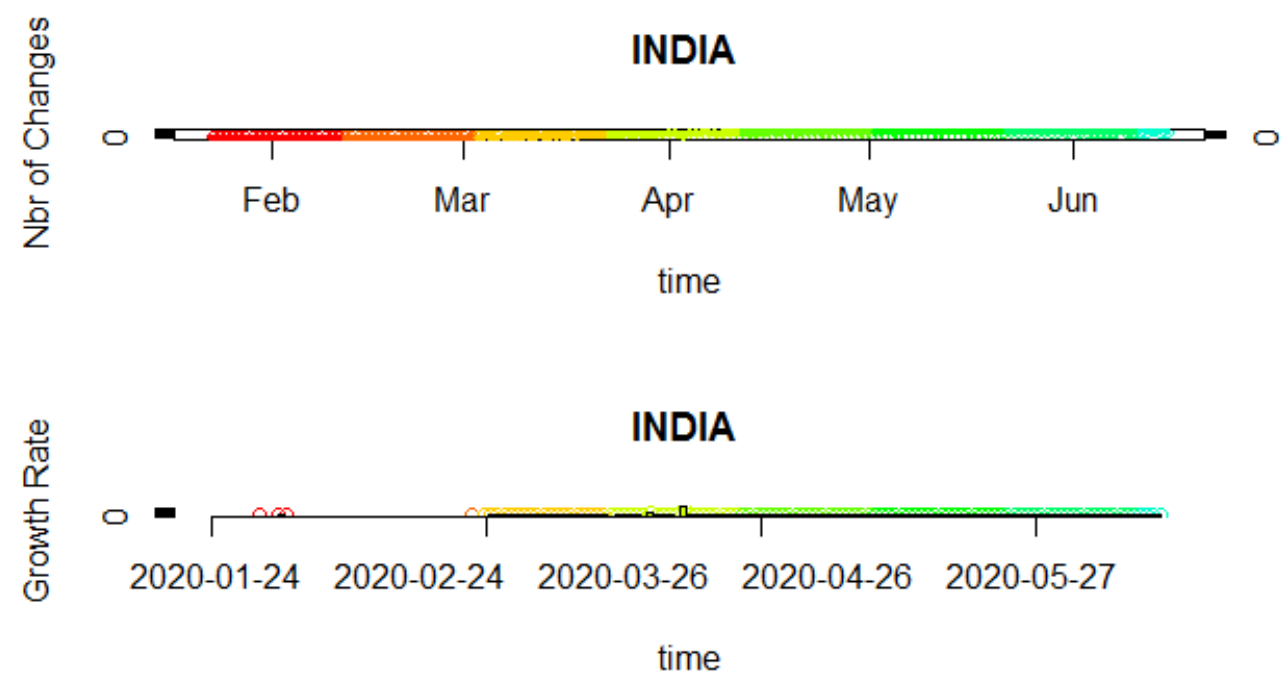

Figure-1: Number of changes and the growth rate of Covid-19 in India 


\section{ii. Total Cases of Covid-19}

(a) Across the globe: Figure-2 represents the graph of the worldwide Covid-19 confirmed, active, recovered and death cases. In the graph given below it is clear that there is an increasing trend in confirmed cases, recovered cases and active cases. But there is almost constant rate in the death cases globally.

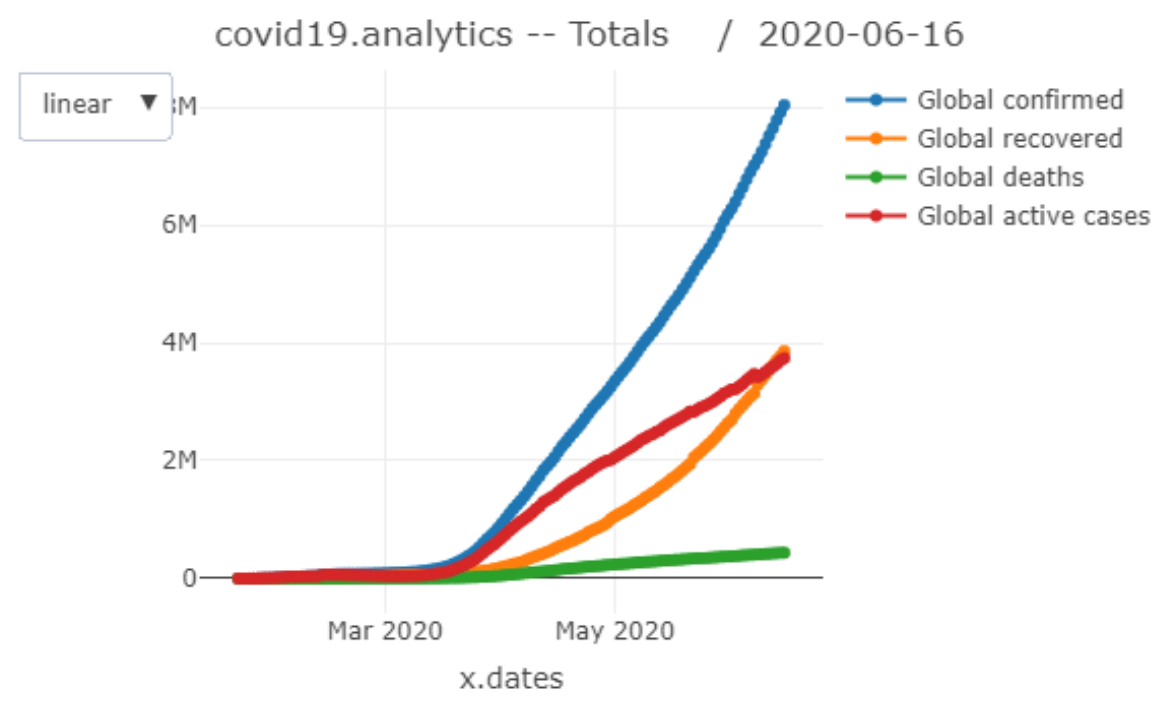

Figure-2: Worldwide Covid-19 confirmed, active, recovered and death cases

(b) Total cases in India with respect to global situation: Figure-3 shows the comparative graph of world and India regarding confirmed, active, recovered and deaths of covid-19 cases. India is very far from the global data in terms of total confirmed cases, recovered cases, active cases and death cases.

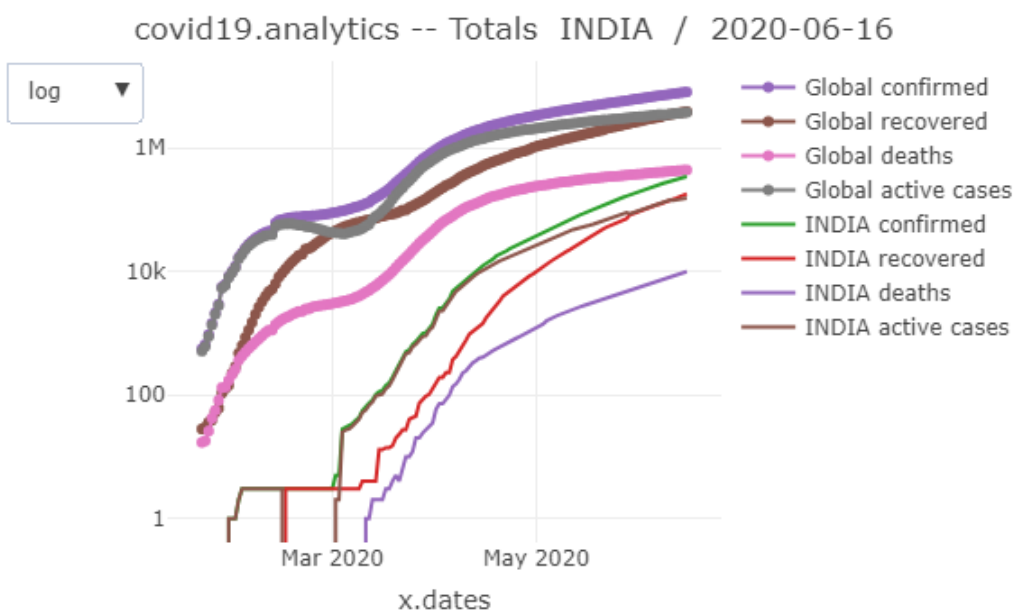

Figure-3: Global and India confirmed, active, recovered and deaths of covid-19 cases 

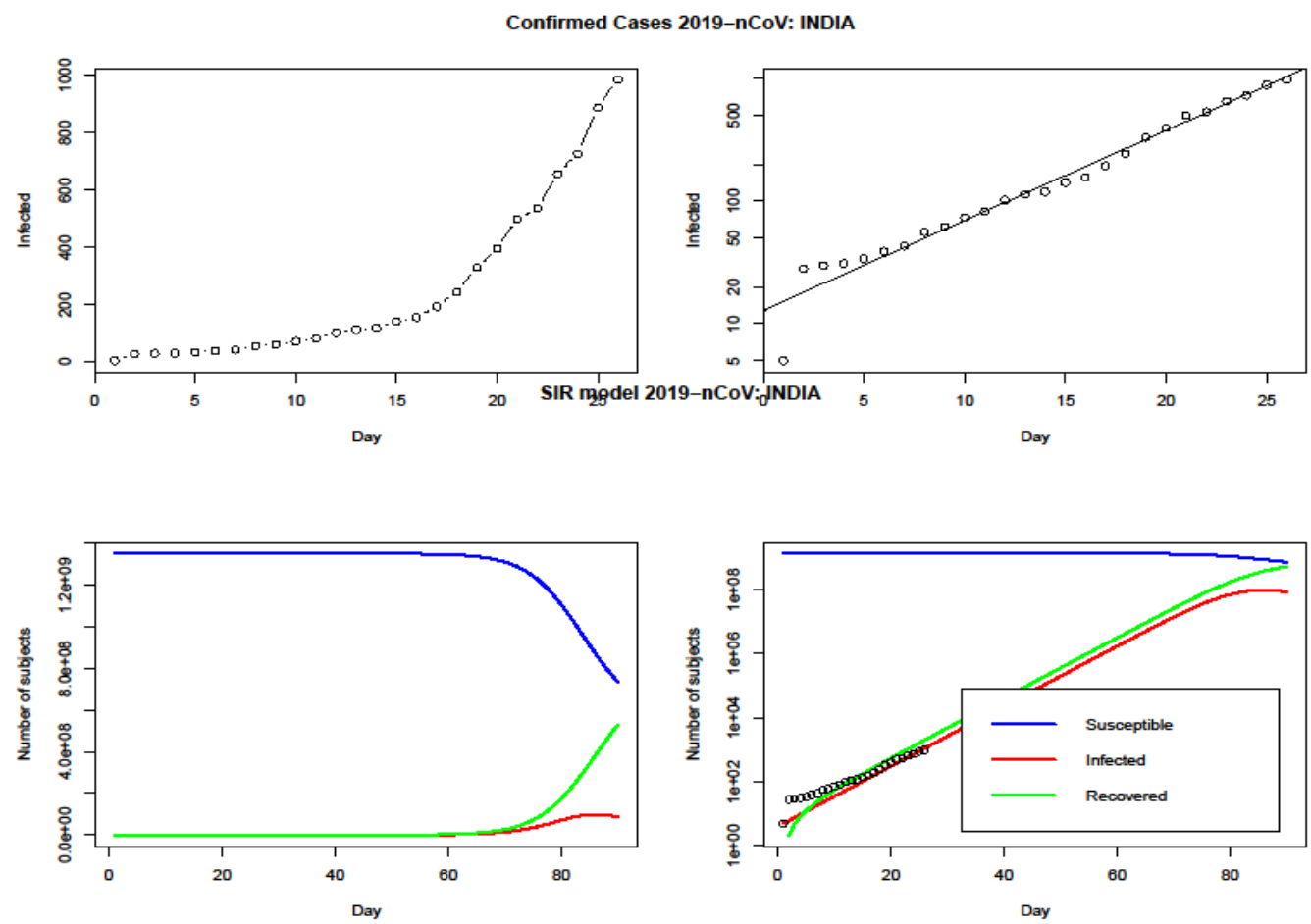

Figure-4: Graph of susceptible, Infected and Recovered cases for SIR model

The fitting of SIR model for India is shown in the following graph. Here it is clear that all three factors having increasing trend. Since, all population is at risk of possible infection, so first factor is always high. It is also clear that in India number of infected people reaches after 80 days of starting of this pandemic. Recovery rate is also increasing with the time.

\section{CONCLUSIONS \& DISCUSSION}

\subsection{Role of Government of India:}

From the above analysis till 16 June 2020, it is clear that India is in critical position in comparison to other developed countries of the world. Seeing the population density of our country, all the efforts made by government like Janta Curfew, lockdown, social distancing, isolation and quarantine are feasible and best possible efforts made by policymakers in the present scenario. Although high level urban to rural migration is also a part of this pandemic which cannot be ignored. It is high time for policymakers to provide basic amenities to this migrant section and make necessary arrangement for their livelihood. Further to get control over the pandemic Covid-19, the complete testing looks feasible which is a big task for the country like India. The suppressive strategies are also good to control the pandemic as in between the lockdown we get time for preparation such as to make more specific hospitals, 
life supporting equipments etc. Thus it is the need of the day to increase testing and make more Covid hospitals with life support system to overcome the problem without much loss.

\subsection{Role of World Health Organization (WHO):}

Although current situation of COVID-19 pandemic The current COVID-19 pandemic is unrivalled, but global has vast experience about lesson obtained from similar disease like SARS etc over several past decades.

As part of WHO's response, the R\&D Blueprint was activated to accelerate diagnostics, vaccines and therapeutics for this novel coronavirus. The foremost aim of this blueprint is to establish a relation and coordination among health personals, researchers and scientists all over the world to discuss latest development in diagnosis, training and innovations to overcome COVID-19.

Scientists from all over the world met at WHO's headquarter in the month of February 2020, to review the available knowledge about this new virus. They agreed to work together to share knowledge, research and innovations to overcome this pandemic and future outbreaks in near future also.

The discussion was focussed on two important goals. First was to promote innovation and research for prevention of spread of this pandemic. The second was to support research priorities that contribute to global research platforms in hopes of learning from the current pandemic response to better prepare for the next unforeseen epidemic.

Based on the experiences obtained from previous outbreaks like SARS, Ebola etc, this R\&D blueprint group of WHO also agreed for mutual coordination in the direction of developing vaccine, new pharmaceutical developments for COVID-19

\section{RECOMMONDATIONS}

Seeing the vulnerability of COVID-19 pandemic, the following recommendations are suggested with special reference to India:

i. An expert committee should be constituted which includes health officials, NGOs, disaster management experts to review the effects of such pandemic in the country. 
ii. A research organization should be developed which specially look such infectious diseases prevalent all over the world and give suggestions to decision makers for Indian context.

iii. Since such pandemic highly affect the economy of the country. So there should be an economic authority which can suggest remedial measures to overcome the situation.

iv. Such pandemic causes lots of migration \& unemployment especially in unorganized sector. So government should initiate special social security schemes to ensure their livelihood.

v. Due to such pandemic, routine health activities like immunization etc suffer a lot, which will affect the future health of the country. So government should take extra efforts to overcome this situation. 


\section{References}

1. Anderson RM (1988) The role of mathematical models in the study of HIV transmission and the epidemiology of AIDS. Journal of Acquired Immune Deficiency Syndromes 1, 241-256.

2. Anderson RM \& May RM (1991) Infectious Diseases of Humans: Dynamics and Control. Oxford University Press, Oxford.

3. Bishop MT, Hart P, Aitchison L et al. (2006) Predicting susceptibility and incubation time of human-to-human transmission of vCJD. Lancet Neurology 5, 393-398.

4. Boudrioua, M.S., Boudrioua, A. (2020), Predicting the COVID-19 epidemic in Algeria using the SIR model, https://doi.org/10.1101/2020.04.25.20079467.

5. Chauhan S., O.P, Dhar, J. (2014), Stability Analysis of Sir Model with Vaccination, American Journal of Computational and Applied Mathematics, 4 (1), 17-23

6. Covid19.analytics (2020). https://mponce0.github.io/covid19.analytics/

7. covid 19.analytics Data (2020). Johns Hopkins University Center for Systems Science and Engineering (JHU CSSE) data repository. https://github.com/CSSEGISandData/COVID-19

8. Dhanwant, J.N. and Ramanathan, V. (2020). Forecasting COVID 19 growth in India using Susceptible-Infected-Recovered (S.I.R) model, axXiv:2004.00696

9. Diekmann O \& Heesterbeek JAP (2000) Mathematical Epidemiology of Infectious Diseases: Model Building, Analysis and Interpretation. John Wiley and Sons, New York.

10. Ferguson NM, Donnelly CA, Woolhouse ME \& Anderson RM (1997) The epidemiology of BSE in cattle herds in Great Britain. II. Model construction and analysis of transmission dynamics. Philosophical Transactions of the Royal Society of London.Series B: Biological Sciences 352, 803-838 
11. Ferguson NM, Cummings DA, Cauchemez S et al. (2005) Strategies for containing an emerging influenza pandemic in Southeast Asia. Nature 437, 209-214.

12. Giordano, G., Blanchini, F., Bruno, R., Colaneri., P., Filippo, A.D., Matteo., A.D., Colaneri, M. (2020). Modelling the COVID-19 epidemic and implementation of population-wide interventions in Italy, Nature Medicine.

13. Huppert, A., Katriel, G. (2013). Mathematical modelling and prediction in infectious disease epidemiology, Clinical Microbiology and Infection,19 (11)

14. Huang, C.,Wang, Y., Li, X., Ren, L., Zhao, J., Hu, Y., Zhang, L., Fan, G., Xu, J., Gu, X., et al. (2020). Clinical features of patients infected with 2019 novel coronavirus in Wuhan, China. Lancet 395 (10223), 497-506.

15. Hamzah, F.A., Lau, C., Nazri, H., Ligot, D.V., Lee, G., Tan, C.L. (2020). CoronaTracker: Worldwide COVID-19 Outbreak Data Analysis and Prediction. [Preprint]. Bull World Health Organ. doi: http://dx.doi.org/10.2471/BLT.20.255695

16. Kermack, W. O., \& McKendrick, A. G. (1927). A contribution to the mathematical theory of epidemics.

Proceedings of the Royal Society A: Mathematical, Physical and Engineering Sciences, 115(772), 700-721.

17. Covid-19.in (2020). https://www.mygov.in/covid-19/?cbps=1.

18. Li, G-H, Zhang, Y-X (2017). Dynamic behaviors of a modified SIR model in epidemic diseases using nonlinear incidence and recovery rates. PLoS ONE 12(4): e0175789. https://doi.org/ 10.1371/journal.pone.0175789

19. Longini IM Jr, Nizam A, Xu S et al. (2005) Containing pandemic influenza at the source. Science 309, 1083-1087.

20. Mahmud, A., Lim, P.W. (2020). Applying the SEIR Model in Forecasting, The COVID-19 Trend in Malaysia: A Preliminary Study. doi: https://doi.org/10.1101/2020.04.14.20065607 medRxiv preprint

21. Rihan, F.A., Anwar, M.N. (2012). Qualitative Analysis of Delayed SIR Epidemic Model with a Saturated Incidence Rate. International Journal of Differential Equations

22. Tobías, A. (2020). Evaluation of the lockdowns for the SARS-CoV-2 epidemic in Italy and Spain after one month follow up. Sci. Total Environ. 725, 138539 (in press). 
23. Wangping J, Ke H, Yang S, Wenzhe C, Shengshu W, Shanshan Y, Jianwei W, Fuyin K, Penggang T, Jing L, Miao L and Yao H (2020). Extended SIR Prediction of the Epidemics Trend of COVID-19 in Italy and Compared With Hunan, China. Front. Med. 7:169. doi: 10.3389/fmed.2020.00169

24. Wallinga J \& Teunis P (2004) Different epidemic curves for severe acute respiratory syndrome reveal similar impacts of control measures. American Journal of Epidemiology 160, 509-516.

25. Wang, D., Hu, B., Hu, C., Zhu, F., Liu, X., Zhang, J., \& Zhao, Y. (2020). Clinical characteristics of 138 hospitalized patients with 2019 novel coronavirus-infected pneumonia in Wuhan, China. Jama, 323(11), 1061-1069.

26. WHO, 2020. https://www.who.int/emergencies/diseases/novel-coronavirus2019/advice- for-public. 